\title{
Sintered Calcined Clay as an Alternative Coarse Aggregate for Asphalt Pavement Construction
}

\author{
Cleudinei Lopes da Silva ${ }^{1}$, Hidembergue Ordozgoith da Frota ${ }^{2}$, Consuelo Alves da Frota ${ }^{1}$ \\ ${ }^{1}$ Department of Civil Engineering, Federal University of Amazonas, Manaus, Brazil \\ ${ }^{2}$ Department of Physics, Federal University of Amazonas, Manaus, Brazil \\ Email: cafrota@ufam.edu.br
}

Received 21 May 2015; accepted 11 August 2015; published 14 August 2015

Copyright (C) 2015 by authors and Scientific Research Publishing Inc.

This work is licensed under the Creative Commons Attribution International License (CC BY). http://creativecommons.org/licenses/by/4.0/

c) (i) Open Access

\section{Abstract}

The aim of this study is to search for a substitute for the natural coarse aggregate in various regions of the world, such as Amazon-Brazil, where this type of material is lacking. The asphalt binder AC 50/70 is mixed with an aggregate obtained from the sinterization of a calcined clay (SACC) as a possible alternative to coarse aggregate material for the construction of asphalt pavements in tropical zones. The dynamic modulus $\left|E^{*}\right|$ of this mixture was measured under strain control mode and in tension control mode. The results are compared with those obtained from AC 50/70 mixed with pebbles, which is currently used as the coarse aggregate in this region. For pavements that work at high temperatures, such as $40^{\circ} \mathrm{C}$, and low frequencies, the mixture with SACC appears to be a viable alternative to coarse aggregate material for the construction of asphalt pavements in tropical zones.

\section{Keywords}

Dynamic Modulus, Viscoelasticity, Sintered Calcined Clay Aggregate, Asphalt

\section{Introduction}

In all regions of the world, there have been increased efforts to identify new materials for use in road construction that obey the economic and environmental conditions based on the natural resources and new technologies of each country. In this context, lightweight aggregates from expanded clay have been studied as substitutes for natural aggregates in the construction of asphalt pavements [1]-[6]. These materials can also be obtained from shale and slate and from sintering fine sediment excavated from reservoirs [7]. Also deserving mention are studies 
regarding the reuse of waste materials from the ceramics industry [8]-[13] and asphalt mixtures that use recycled tire rubber [14]-[17].

In the Amazon region in northern Brazil, the construction of pavements is a great challenge for civil engineering due to the lack of coarse aggregate. The natural sources of aggregate materials are distant from the urban areas. The predominant geological formations consist of claystone, siltstone, and sandstone. Since the Tertiary period, these rocks have undergone intense lateritic weathering, resulting in a thick layer of residual soil on which the Amazon rainforest spreads. The rock material is located at a great depth from the surface such that its exploitation as a source of aggregate material for civil construction is notably expensive. The transportation of those materials from the distant surface deposits to the urban areas should generally be conducted via the river network that crosses the region. The scarcity of this material, associated with the poor navigability of the rivers for six months each year (the dry season) and the great distances involved in its transportation, makes its cost prohibitive to the civil construction industry. In the absence of the traditionally used granular materials, the pavements in this region are often constructed using pebbles collected from the edges and the bottom of the local rivers. However, the continued large-scale exploitation of these materials could cause serious environmental problems in the very near future with a strong impact on the Amazon rainforest. The sintered aggregate of calcined clay (SACC) may represent a viable alternative to coarse aggregate material for the construction of pavements in the Amazon region.

For the above reasons, we studied the Dynamic Modulus $\left|E^{*}\right|$ of asphalt binder AC 50/70 mixed with an aggregate obtained from the sinterization of a calcined clay under cyclic loading [18]. We performed the cyclic testing in two different ways: in strain control mode by applying tension-compression loading [19] [20] and in tension control mode. The mixture's Dynamic Modulus $\left|E^{*}\right|$ was compared with that of AC 50/70 mixed with pebbles, which is the aggregate currently used in pavement construction in the Amazon-Brazil region. We observed that at high temperatures, such as $40^{\circ} \mathrm{C}$ or higher, as is observed in tropical regions, and low frequencies, the first mixture appears stronger than the second. In this case, the sintered aggregate of calcined clay (SACC) may represent a viable alternative to coarse aggregate material for the construction of pavements in tropical regions.

\section{Materials and Methods}

\subsection{Material}

The materials studied under cyclic loading are composed of a mixture of asphalt concrete AC50/70 and the coarse aggregates SACC and pebbles. The latter is what is currently largely used in the asphalt mixtures of pavements, the exploitation of which is responsible for the deterioration of the Amazon rivers beds. In this study, pebbles are used only as a comparison to SACC, which is studied as an alternative for the serious environmental problems created by the exploitation of pebbles.

1) Aggregates

The SACC was obtained from typical clay soil of Amazon-Brazil. The SACC was characterized according to the Brazilian Association of Technical Standards (ABNT) using NBR-7181 for the grain size, NBR-6459 for the liquid limit and NBR-7180 for the plastic limit. The calcination potentiality of the raw clay to form aggregates was obtained following the instructions of the Federal National Department of Transport Infrastructure (DNIT) of Brazil (ME222, ME223 and ME225). To produce aggregates from raw clay, massive bricks, with dimensions of $60 \mathrm{~mm} \times 110 \mathrm{~mm} \times 200 \mathrm{~mm}$ and two longitudinal holes, were crushed into grain-sized portions.

The two coarse materials were evaluated according to the instructions of the American Society for Testing and Materials (ASTM). The grain size and the Los Angeles abrasion value follow ASTM-C136 and ASTMC131, respectively. The apparent specific gravity (Gsa), bulk specific gravity (Gsb), bulk specific gravity in the condition saturated surface dry (Gsbssd) and absorption were obtained via adherence to ASTM-C127. The coarse materials were also characterized in relation to the Rodded Unit Weight (Wur) and Loose Unit Weight (Wul) following the American Association of State Highway and Officials (AASHTO).

Three fine aggregates were used to constitute the asphalt mixtures: two sands, obtained from the local supplier, with different grain sizes, and the powder resulting from the procedure of brick grinding. They were characterized by ASTM-C136 (grain size), ASTM-C128 (Gsa, Gsbssd and absorption) and Rodded Unit Weight (AASHTO).

The grain-size distributions for the natural soil (NSOIL), which was used to produce the sintered aggregate of 
calcined clay, are shown in Figure 1: the sands MAO and COA, contained in AC 50/70 mixtures with SACC and pebbles, respectively; the artificial sand, obtained from powder of SACC (SACC-P); and the coarse aggregates SACC and pebbles. The consistency indexes of NSOIL are: $\mathrm{LL}=48 \%, \mathrm{PL}=22 \%$ and PI $=26 \%$. From these results, NSOIL is classified as belonging to the groups A7-6 and CL, according to the AASHTO Classification System and Unified Classification System, respectively.

The mineralogy of the natural soil used to obtain the sintered aggregate consists of kaolinite, goethite, hematite, illite and quartz. The characterizations of the coarse aggregate and the sand are shown in Table 1 and Table 2, respectively.

2) Binder and filler

The petroleum asphalt cement AC 50/70 was used as the binder, and rheological analysis, performed according to the Superior Performance Asphalt Pavements, classified it as PG64 + 2. The Portland cement, the filler in the composition of the asphalt mixtures, exhibits $3.15 / \mathrm{cm}^{3}$ of apparent specific gravity and a $0.075 \mathrm{~mm}$ sieve passing percentage of $100 \%$ according to DNIT-ME085 and DNIT-ME367, respectively.

\subsection{Methods}

The mechanical behavior of asphalt mixtures depends largely on temperature, varying from elastic to nonlinear viscoelastic, as well as on rate of application of the load or strain. These characteristics are derived primarily from the asphalt binder. In this study, we perform the Dynamic Modulus $\left|E^{*}\right|$ under both constant tension and constant strain regimes. This propriety was obtained for two types of AC 50/70 mixtures: with SACC, as an alternative coarse material, and with pebbles, which is a conventional coarse aggregate used in civil engineering and taken as the reference material for SACC.

1) Samples

Following the Superpave system for the granulometric compositions of asphalt mixtures, the Nominal Maximum Sizes (NMS) adopted was $19.00 \mathrm{~mm}$. The percentages of mineral components of the mixtures were defined according to the Bailey method [21].

In Table 3, we present the composition of the concrete asphalt mixture with SACC and pebbles. The AC 50/70 mixture with SACC consists of 74.25\% SACC, $14.03 \%$ SACC sand (SACC-P), 10.32\% Coari sand (COA) and $1.40 \%$ Portland cement. The AC 50/70 mixture with pebbles consists of $67.20 \%$ pebbles, $29.7 \%$ Manaus sand (MAO) and 3.1\% Portland cement.

The air voids (Va) and voids filled with asphalt (VFA) were determined by compacting the mixtures according to the Marshall method of dosage. Based on these parameters, and following the method of DNIT, the content of the composite was determined; the volumetric parameters are shown in Table 4. Aiming to simulate the

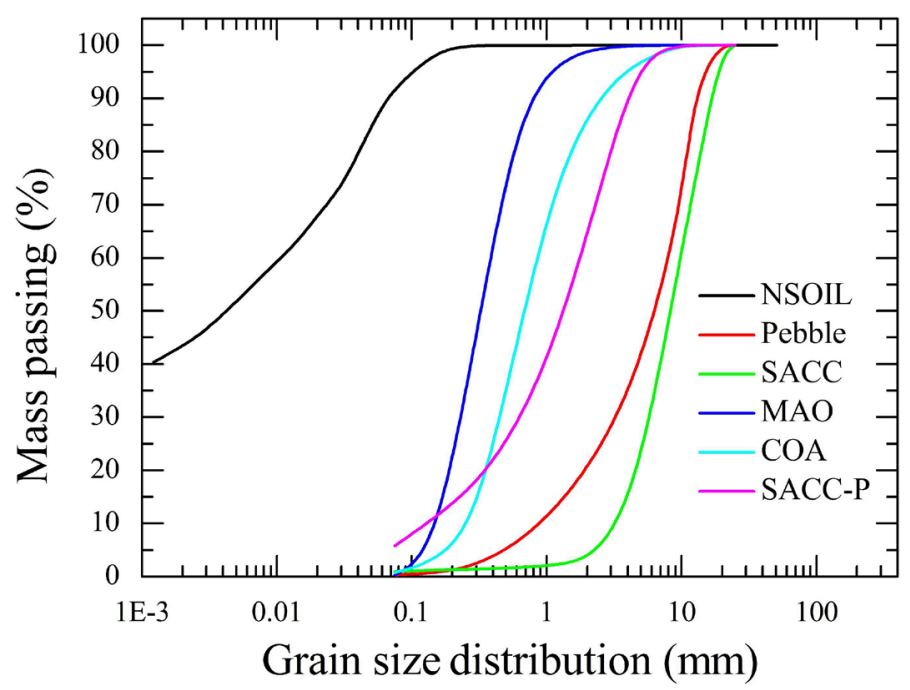

Figure 1. Grain size distribution for the natural soil (NSOIL), the sands MAO and COA, the artificial sand SACC-P, and the coarse aggregates SACC and pebbles. 
Table 1. Coarse aggregate characterization.

\begin{tabular}{cccc}
\hline Tests & SACC & Pebble & Method \\
\hline Bulk specific gravity, Gsb $\left(\mathrm{g} / \mathrm{cm}^{3}\right)$ & 1.855 & 2.626 & ASTM C-127 \\
$\begin{array}{c}\text { Bulk Specific Gravity in the condition } \\
\text { saturated surface dry, Gsbssd }\left(\mathrm{g} / \mathrm{cm}^{3}\right)\end{array}$ & 2.133 & 2.636 & \\
Apparent Specific Gravity, Gsa $\left(\mathrm{g} / \mathrm{cm}^{3}\right)$ & 2.571 & 2.643 & 0.0 \\
Absorption $(\%)$ & 15.0 & 1894.6 & AASHTO T-19 \\
Loose Unit Weight, Wul $\left(\mathrm{kg} / \mathrm{m}^{3}\right)$ & 1062.0 & 1906.32 & ASTM C-131 \\
Rodded Unit Weight, Wur $\left(\mathrm{kg} / \mathrm{m}^{3}\right)$ & 1126.35 & 37.0 & \\
Los Angeles abrasion $(\%)$ & 70.0 & &
\end{tabular}

Table 2. Sand characterization.

\begin{tabular}{ccccc}
\hline Sample & MAO & COA & SCCA-P & Method \\
\hline Gsb $\left(\mathrm{g} / \mathrm{cm}^{3}\right)$ & 2.632 & 2.627 & 1.790 & ASTM C 128 \\
Gsbssd $\left(\mathrm{g} / \mathrm{cm}^{3}\right)$ & 2.692 & 2.706 & 2.167 & \\
Absorption $(\%)$ & 0.00 & 0.00 & 18.96 & AASHTO T-19 \\
Wur $\left(\mathrm{kg} / \mathrm{m}^{3}\right)$ & 1675.9 & 1782.20 & 1375.71 & \\
\hline
\end{tabular}

Table 3. AC mixture composition with SCCA and pebbles.

\begin{tabular}{ccc}
\hline Components & SCCA mixture & Pebble mixture \\
SCCA (\%) & 74.25 & - \\
Pebble (\%) & - & 67.2 \\
SCCA-P Sand (\%) & 14.03 & - \\
COA Sand (\%) & 10.32 & - \\
MAO sand (\%) & - & 29.7 \\
Portland cement (\%) & 1.40 & 3.10 \\
\hline
\end{tabular}

Table 4. Volumetric parameters.

\begin{tabular}{ccc}
\hline Parameters & SACC & Pebble \\
\hline Content of AC (\%) & 9.4 & 4.5 \\
Bulk specific gravity, Gmb (\%) & 1.778 & 2.288 \\
Maximum specific gravity, Gmm (g/cm $\left.{ }^{3}\right)$ & 1.842 & 2.383 \\
Air voids, Va (\%) & 3.5 & 4.0 \\
Voids in mineral aggregates, VMA (\%) & 15.98 & 18.78 \\
Voids filled with asphalt, VFA (\%) & 78.1 & 78.7 \\
\hline
\end{tabular}

short-termaging effect, before compaction, the mixtures remained in an oven at $10^{\circ} \mathrm{C}$ above the temperature of compaction for two hours. Based on the guidelines of DNIT, its preparation and compaction temperatures were determined.

To perform the dynamic module test, the samples were prepared with $100 \mathrm{~mm}$ diameters and $200 \mathrm{~mm}$ heights. The samples were subjected to pulses of sinusoidal loads, under strain control mode (by applying axial tensioncompression loading) and under tension control mode, at temperatures of $-5^{\circ} \mathrm{C}, 10^{\circ} \mathrm{C}, 25^{\circ} \mathrm{C}$ and $35^{\circ} \mathrm{C}$ and load application frequencies of $0.01,0.05,0.10,0.50,1.00,5.00,10.00$ and $25.00 \mathrm{~Hz}$. To prevent sample damage, the 
axial deformation did not exceed the value of $75 \mu \varepsilon$. The tests were performed using a Universal Testing Machine UTM-14, made by IPC Co. Ltd. of Australia. The deformations in the samples were monitored with micros LVDTs (Linear Variable Differential Transducers). Such devices were bonded at four diametrically opposed points of the samples at distances of $25 \mathrm{~mm}$ to150 $\mathrm{mm}$ from each face.

\section{Results and Discussion}

\subsection{The Master Curve}

The Dynamic Modulus $\left(E^{*}\right)$ of AC 50/70 mixtures with SACC and pebbles was obtained under both the strain control mode and tension control mode. In Figure 2(a), we present $\left|E^{*}\right|$ at constant tension regime for AC 50/70 mixed with SACC for three different temperatures, $T=40^{\circ} \mathrm{C}, T=10^{\circ} \mathrm{C}$ and $T=-5^{\circ} \mathrm{C}$, as a function of the frequency, $\omega$. In Figure 2(b), we show $\left|E^{*}\right|$ as a function of the reduced frequency $\omega_{R}=a_{T} \omega$, where $a_{T}$ is a temperature shift factor [22].

Taking a reference temperature $T_{0}$ in a double logarithmic scale, $\log \left(\alpha_{T}\right)$ is the amount of shift necessary to form a unique curve from different temperatures, known as a master curve. In the present study, the reference temperature $T_{0}$ is taken as $10^{\circ} \mathrm{C}$. The results present in Figure 2(b) are compared with the master curve obtained by Zheng et al. [23], analyzing asphalt mixtures over various frequency and temperature ranges. According to these authors, $\left|E^{*}\right|$ of the mixtures as a function of the reduced frequency is represented by the function

$$
\left|E^{*}\right|=\frac{E_{g}^{*}}{\left[1+\left(\omega_{c} / \omega_{R}\right)^{k}\right]^{m_{c} / k}},
$$

where $E_{g}^{*}$ is the complex modulus in the limit $\omega_{R} \rightarrow \infty, \omega_{c}$ is a frequency location parameter, and $k$ and me are
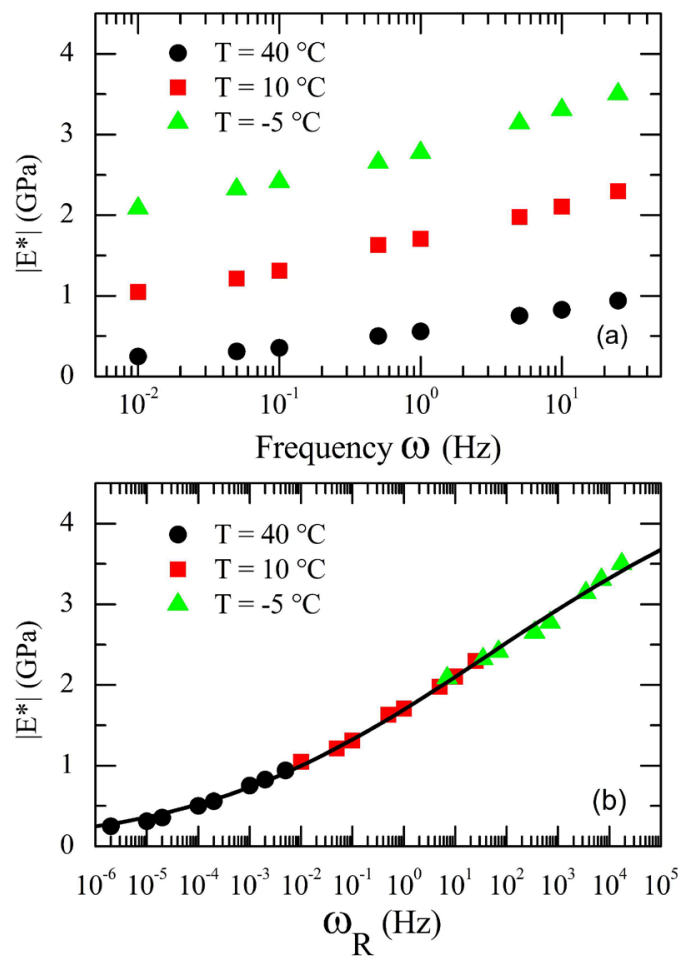

Figure 2. (a) Elastic Modulus under controlled stress for the AC mixture with SACC as a function of the frequency $\omega$ for different temperatures. (b) The master curve as a function of the reduced frequency $\omega_{R}$ obtained from the results shown in (a). 
dimensionless shape parameters. The parameters $\omega_{c}, k$ and $m_{e}$ are estimated using a minimum squared error fitting procedure. This function presents a spectrum that increases monotonically from zero, at $\omega_{R}=0$, until its saturation at $E_{g}^{*}$ as $\omega_{R} \rightarrow \infty$. The width of the relaxation spectrum is characterized by a shape index defined as $\mathrm{R}=$ $\left(m_{e} / \mathrm{k}\right) \log 2$. The higher this index, the more gradual the transition from the elastic to the viscous behavior is. The solid lines in Figure 2(b) represent the quality of the fit to Equation (1) for each sample.

In Figure 3(a), we present the values of $\left|E^{*}\right|$ as a function of $\omega_{R}$ under both constant tension and constant strain regimes, and we observe good agreement between the two methods. In Figure 3(b), we present the temperature shift factor $a_{T}$ as a function of $T$ obtained under constant tension (C. Tension) and constant strain (C. Strain) regimes, with both coinciding and approaching a straight line.

\subsection{Dynamic Modulus of SACC versus Pebble}

The comparison between the Dynamic Modulus of the mixtures of AC 50/70 with SACC and with pebbles is shown in Figure 4, where we present, in (a), $\left|E^{*}\right|$ as a function of the reduced frequency $\omega_{R}$ and, in (b), $\left|E^{*}\right|$ as a function of the frequency $\omega$, obtained under constant stress. In (a), the black squares and the red circles represent the AC 50/70 mixture with pebbles and the AC 50/70 mixture with SACC, respectively. From these results, we observe that for low reduced frequency $\omega_{R}$, the mixture with SACC is stronger than the mixture with pebbles, and, for high $\omega_{R}$, the inverse occurs and the mixture with pebbles is stronger than the mixture with SACC. For a given frequency, a small reduced frequency corresponds to a high temperature environment. In (b), we verify that for $T=-5^{\circ} \mathrm{C}$ and $T=10^{\circ} \mathrm{C}$, the mixture with pebbles is stronger than the mixture with SACC. When increasing the temperature and for low frequency, the mixture with SACC becomes stronger than that with pebbles. For $T=40^{\circ} \mathrm{C}$, for example, the mixture with SACC is stronger than the mixture with pebbles for frequencies lower than $1.0 \mathrm{~Hz}$. In tropical zones, the temperature of asphalt pavement can rise to $70^{\circ} \mathrm{C}$. Our results shows
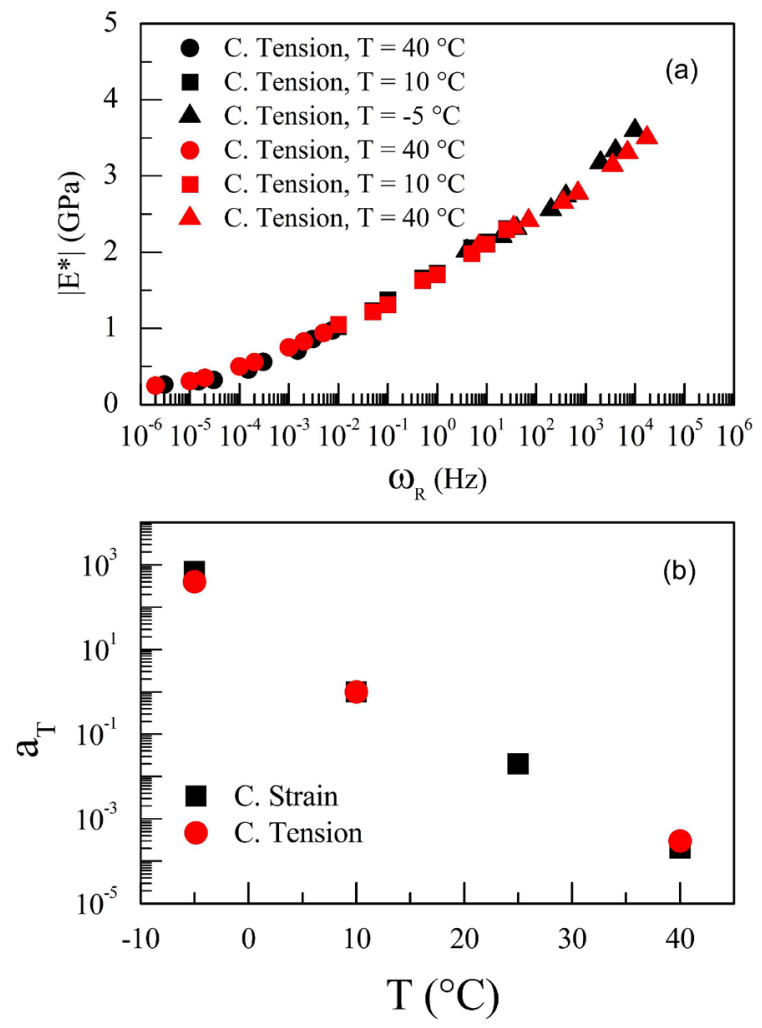

Figure 3. (a) Elastic Modulus under controlled stress (C. Stress) and controlled strain (C. Strain) for the AC mixture with SACC as a function of the reduced frequency $\omega_{R}$ for different temperatures. (b) The temperature shift factor $a_{T}$ obtained from the results shown in (a). 

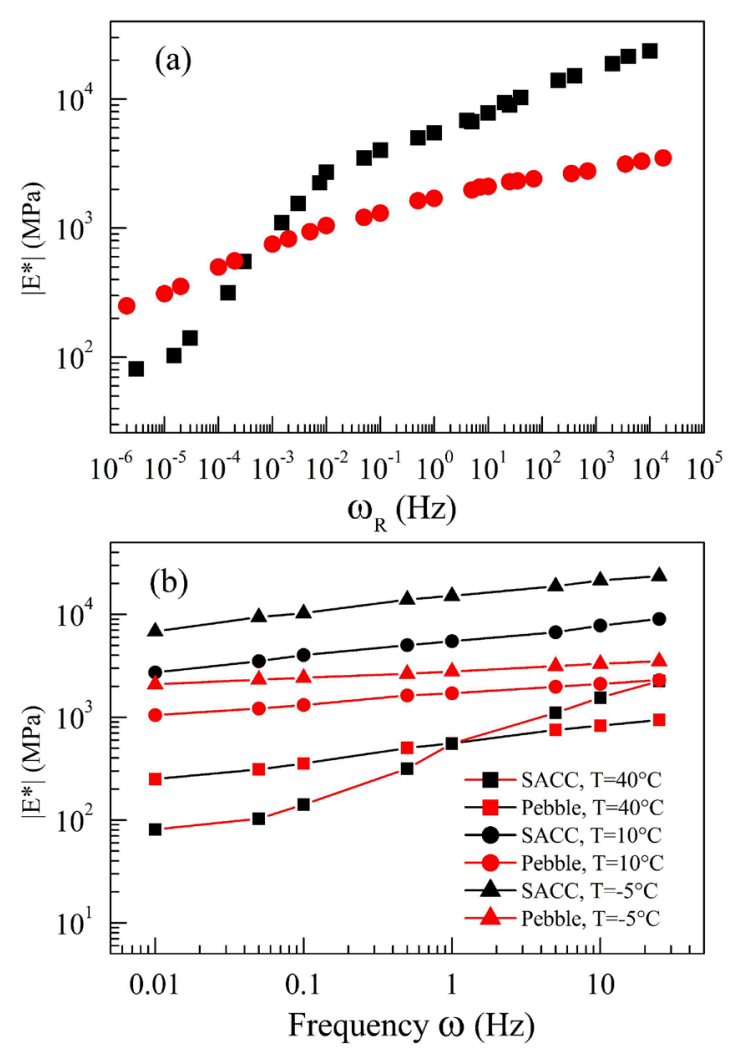

Figure 4. Dynamic Modulus of AC 50/70 mixed with SACC compared to the Dynamic Modulus of AC 50/70 mixed with pebbles.

that, in such zones and where sedimentary soil is more plentiful, with the lack of granular material, the sintered aggregate of calcined clay (SACC) can be a good alternative to natural granular aggregate for concrete asphalt mixtures.

\section{Conclusion}

We investigated the application of the sintered aggregate of calcined clay (SACC) in mixtures of concrete asphalt for road pavement. We consider CA 50/70 as the binder, and SACC and pebbles as the coarse material. The Dynamic Modulus $\left|E^{*}\right|$ of the mixtures was measured under cyclic loading. For high temperatures and low frequencies, the mixture with SACC appears stronger than the mixture with pebbles. This temperature condition is observed in tropical zones around the world. For such regions, where there is a lack of natural granular material, the sintered aggregate of calcined clay can be a good option for use as the coarse material in mixtures of concrete asphalt for road pavement.

\section{Acknowledgements}

The authors acknowledge the National Council for Scientific and Technological Development (CNPq) and the Foundation for Research Support of the State of Amazonas (FAPEAM) for their financial support.

\section{References}

[1] Losa, M., Leandri, P. and Bacci, R. (2008) Mechanical and Performance-Related Properties of Asphalt Mixes Containing Expanded Clay Aggregate. Transportation Research Record, 2051, 23-30. http://dx.doi.org/10.3141/2051-04

[2] Lehmann, H.L. and Adam, V. (1959) Use of Expanded Clay Aggregate in Bituminous Construction. Highway Research Board Proceedings, 38, 398-407. 
[3] Aams, V. and Shah, S.C. (2008) Evaluation of Open-Graded Plan-Mix Real Surfaces for Correction of Slippery Pavements. Transportation Research Record, 523, 88-96.

[4] Mallick, R.B., Hooper, F.P., O’Brien, S. and Kashi, M. (2004) Evaluation of Use of Synthetic Lightweight Aggregate in Hot-Mix Asphalt. Transportation Research Record, 1891, 1-7. http://dx.doi.org/10.3141/1891-01

[5] Canestrari, F.M., Bocci, G., Ferroti, G. and Pasquini, P. (2007) Mechanical Caracterization of Environmentally Friendly Mixtures. Proceeding of the International Conference on Advanced Characterization of Pavement and Soil Engineering Materials, Greece, June 2007, 1643-1652.

[6] Takahashi, T. and Partl, M.N. (2001) Improvement of Mix Design for Porous Asphalt. Road Materials and Pavement Design, 2, 283-296. http://dx.doi.org/10.1080/14680629.2001.9689904

[7] Shena, D.-H., Wua, C.-W. and Chong, D.J.-C. (2008) Performance Evaluation of Porous Asphalt with Granulated Synthetic Lightweight Aggregate. Construction and Building Materials, 22, 902-910. http://dx.doi.org/10.1016/j.conbuildmat.2006.12.008

[8] Tay, J.H. (1987) Brick Manufacture from Sludge. Journal of Environmental Engineering, 113, 278-284. http://dx.doi.org/10.1061/(ASCE)0733-9372(1987)113:2(278)

[9] Churchill, M. (1994) Aspect of Sewage Sludge Utilization and its Impact on Brick Making. Global Ceramic Review, 1, 18-21.

[10] Perez, J.A, Terradas, R., Manent, M.R., Seijas, M. and Martinez, S. (1996) Inertization of Industrial Wastes in Ceramic Materials. Industrial Ceramics, 16, 7-10.

[11] Dondi, M., Marsigli, M. and Fabbri, B. (1997) Recycling of Industrial and Urban Wastes in Brick Production: A Review. Tile \& Brick International, 13, 218-225.

[12] Alleman, J.E. (1987) Beneficial Use of Sludge in Building Components. Interbrick, 3, 14-16.

[13] Riberio, M.J., Tulyaganov, D.U., Ferreira, J.M. and Labrincha, J.A. (2002) Recycling of Al-Rich Industrial Sludge in Refractory Ceramic Pressed Bodies. Ceramics International, 28, 319-326. http://dx.doi.org/10.1016/S0272-8842(01)00097-9

[14] Bertollo, S.M., Bernucci, L.B., Fernandes, J.L. and Leite, L.M. (2004) Mechanical Properties of Asphalt Mixtures Using Recycled Tire Rubber Produced in Brazil-A Laboratory Evaluation. Proceedings of 83rd TRB Annual Meeting, Washington DC, 11-15 January 2004, TRB2004-002077.

[15] Zborowski, A., Sotil, A., Kaloush, K.E. and Way, G.B. (2004) Material Characteristics of Asphalt Rubber Mixtures. Proceedings of 83rd TRB Annual Meeting, Washington, DC, 11-15 January 2004, TRB2004-003136.

[16] Santagata, F.A., Canestrari, F. and Pasquini, E. (2007) Mechanical Characterization of Asphalt Rubber-Wet Process. Proceedings of 4th International SIIV Congress-Advances in Transportation Infrastructures and Stakeholders Expectation, Palermo, 12-14 September 2007, A163.

[17] Pasquini, E. (2009) Advanced Characterization of Innovative Environmentally Friendly Bituminous Mixtures. PhD Thesis, Istituto di Idraulica e Infrastrutture Viarie, Università Politecnica delle Marche, Agraria.

[18] Sides, A., Uzan, J. and Perl, M. (1985) A Comprehensive Visco-Elastoplastic Characterization of Sand-Asphalt under Compression and Tension Cyclic Loading. ASTM Journal of Testing and Evaluation, 13, 49-59. http://dx.doi.org/10.1520/JTE10760J

[19] Di Benedetto, H. and de la Roche, C. (1998) State of the Art of Stiffness Modulus and Fatigue of Bituminous Mixtures. In: Francken, L., Ed., RILEM Report 17, Bituminous Binders and Mixes, CRC Press, London, 137-180.

[20] Doubbaneh, E. (1995) Comportement Mécanique des Enrobes Bitumineux des “Petites” Aux “Grandes” Déformations. PhD Thesis, L’institut Nations Des Sciences Appliquées De Lyon, Laboratoire Géomatériaux du Département de Génie Civil, Lyon.

[21] Vavrik, W.R., Huber, G.A., Pine, W.J., Carpenter, S.H. and Bailey, R. (2002) Bailey Method for Gradation Selection in HMA Mixture Design. Transportation Research Record, Circular No. E-C044.

[22] Williams, M.L., Landel, R.F. and Ferry, J.D. (1995) The Temperature Dependence of Relaxation Mechanisms in Amorphous Polymers and Other Glass-Forming Liquids. The Journal of the American Chemical Society, 77, 37013707. http://dx.doi.org/10.1021/ja01619a008

[23] Chen, Z., Wu, S.-P., Zhu, Z.-H. and Liu, J.-S. (2008) Experimental Evaluation on High Temperature Rheological Properties of Various Fiber Modified Asphalt Binders. Journal of Central South University of Technologya, 15, 135-139. http://dx.doi.org/10.1007/s11771-008-0332-0 